\title{
Jet, Ultrasonic, and Mesh Nebulizers: An Evaluation of Nebulizers for Better Clinical Outcomes
}

\author{
Arzu Arl \\ Department of Respiratory Therapy, Georgia State University, Atlanta, GA, USA
}

\begin{abstract}
For over a century, nebulizers have been commonly used to deliver aerosolized medications in the treatment of patients with pulmonary diseases. They are the aerosol device of choice when patients can not coordinate inhalation and actuation needed for the use of the pressurized metered-dose inhalers (pMDIs) or are not able to provide the necessary inspiratory flow required by the dry powder inhaler (DPI) for effective aerosol drug delivery. Three types of nebulizers exist: (1) jet nebulizers, (2) ultrasonic nebulizers, and (3) mesh nebulizers. The purpose of this paper is to explain the types of nebulizers available on the market and to evaluate their efficiencies in aerosol drug delivery while suggesting strategies for the optimal treatment of patients with pulmonary diseases.
\end{abstract}

Keywords: Nebulizers, aerosols, inhalation therapy

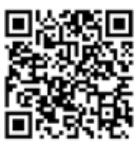

Received date: 20.12 .2013 Accepted date: 02.01 .2014

Address for correspondence Arzu Arı, Department of Respiratory Therapy, Georgia State University, Atlanta, GA, USA E-mail: arzuari@hotmail.com

(C) Copyright 2014 Turkish Respiratory Society (TRS) DOI: 10.5152/ejp.2014.00087

-Available online at www.eurasianjpulmonol.com
Delivery of aerosolized drugs was revolutionized in the 1950s with the development of nebulizers and pressurized metered-dose inhalers. Nebulizers transform liquid formulations and suspension into medical aerosol. In the past few years, there have been advances in the development of new nebulizers that hold the promise to improve aerosol drug delivery to patients with pulmonary diseases. Nebulizers are divided into three categories: (1) jet nebulizers, (2) ultrasonic nebulizers, and (3) mesh nebulizers. While jet nebulizers are commonly used for the treatment of patients with pulmonary diseases, they are bulky and require a power source. Due to aerosolized droplets and solvent vapor that saturates the outgoing air, jet nebulizers cool the drug solution in the nebulizer and increase solute concentration in the residual volume. Although ultrasonic nebulizers are more efficient and compact than jet nebulizers, they can not be used to deliver proteins or suspensions. With the development of mesh nebulizers that use lower-frequency waves, heating issues that denature proteins during aerosol therapy are eliminated. Also, it has been shown that mesh nebulizers are suitable for delivery of suspensions, liposomes, and nucleic acids (1-5). Since there is a large number of nebulizers in each category that have been introduced to the market, the purpose of this paper is to explain the types of nebulizers available and to evaluate their efficiencies in aerosol drug delivery. In addition, strategies for optimal inhalation treatment of patients with pulmonary diseases will be investigated.

\section{JET NEBULIZERS}

Traditionally, jet nebulizers have been used for the treatment of pulmonary diseases. These nebulizers require 2 to $10 \mathrm{~L} / \mathrm{min}$ of pressurized gas to draw medication up through a capillary tube from the nebulizer reservoir in order to generate a wide range of particle sizes that are blasted into one or more baffles, which take larger particles out of suspension and return them to the reservoir.

Jet nebulizers are effective in delivering formulations that can not be delivered with pressurized metered-dose inhalers (pMDIs) and dry powder inhalers (DPIs). For instance, antibiotics, mucolytics, liposomal formulations, and recombinant products, such as Pulmozyme ${ }^{\circledast}$ Inhalation Solution, are some of the medications that can be delivered via jet nebulizers. On the other hand, jet nebulizers can be difficult to use because of their need for compressed gas and additional tubing. Also, several 
studies have proven their inefficiencies in drug delivery (6-8). For these reasons, new types of jet nebulizers have been developed over the years. Through improvements in the nebulizer design, new jet nebulizers either have reservoirs that conserve aerosols or utilize baffles that reduce the size of large particles and increase the efficiency of aerosol therapy. They also have breath-enhanced aerosol production that leads to greater drug delivery, a larger fine-particle fraction, and less drug loss during expiration.

Jet nebulizers are divided into four categories: (1) jet nebulizers with a corrugated tube, (2) jet nebulizers with a collection bag, (3) breath-enhanced jet nebulizers, and (4) breath-actuated jet nebulizers.

\section{Jet Nebulizers with a Corrugated Tube}

Jet nebulizers with a corrugated tube are conventional constant-output nebulizers that generate continuous aerosol during inspiration, expiration, and breath-hold. Although the corrugated tube attached to the jet nebulizer acts as a reservoir, there is still significant drug loss during expiration with this type of nebulizer. Other disadvantages of these nebulizers include limited portability, requirements for compressed air/gas sources for operation, and variability between nebulizers (9-11). While jet nebulizers with a corrugated tube have several disadvantages, they are easy to use and have a good profile on patient compliance with treatment (12).

\section{Jet Nebulizers with a Collection Bag}

A jet nebulizer with a collection bag is considered a dosimetric nebulizer that releases aerosol only during inhalation. Aerosols generated during expiration are stored in the collection bag and given to the patient with the next inspiration through a one-way valve that is located between the mouthpiece and the collection bag. The Circulaire (Westmed INC, Tucson, AZ) is an example of this type of nebulizer. It has a better clinical profile than jet nebulizers with corrugated tubing, as it improves peak expiratory flow, heart rate, and respiratory rate in patients admitted to the emergency department due to bronchospasm (13). In addition, the Circulaire decreases the amount of drug escaping into the environment, providing less exposure to caregivers $(14,15)$ while improving aerosol drug delivery to the patient's lungs (14-16).

\section{Breath-Enhanced Jet Nebulizers}

Breath-enhanced jet nebulizers release more aerosol during inhalation through one-way valves in the mouthpiece. They generate aerosols using a negative pressure created by a patient's inspiratory effort. PARI LC Plus, (PARI, Midlothian, VA) PARI LCD (PARI, Midlothian, VA), and NebuTech, (Salter Labs, Arvin, CA) are examples of breath-enhanced jet nebulizers. Although the efficiency of breath-enhanced nebulizers is better than jet nebulizers with corrugated tubing $(17,18)$, it must be noted that not all breath-enhanced nebulizers have the same efficiency (19), due to differences in residual volume and particle size.

\section{Breath-Actuated Jet Nebulizers}

Breath-actuated jet nebulizers (BANs), like the AeroEclipse (Monoghan/Trudell Medical International, London, Ontario, Canada), sense the patient's inspiratory flow and deliver aerosol only on inspiration. Therefore, these nebulizers decrease drug wastage during aerosol therapy but can increase treatment time (20). The AeroEclipse has a green button on the top part of the nebulizer that moves up and down and shows the patient when the nebulizer is actuat- ed. The actuator button moves down and starts generating aerosol when the patient inhales. The actuator moves back up to its closed position during expiration in order to stop aerosol production until the patient's next breath. Since it generates aerosol in response to the patient's inspiratory maneuver, it has a low level of drug loss to the environment. The AeroEclipse is easy to use and is associated with a lower occurrence of adverse events (21). A recent clinical study reported that the breath-actuated nebulizer was more effective in reducing lung hyperinflation and respiratory frequency in patients with acute exacerbation of chronic obstructive pulmonary disease (COPD) (22). Also, patients and respiratory therapists had greater satisfaction with the BAN in adult patient populations, compared to the jet nebulizer with a corrugated tube (21). Although studies evaluating the efficiency of the breath-actuated nebulizers in pediatric patient populations are limited, an in vitro study showed that breath-actuated nebulization generated a lower lung dose and higher treatment time in a simulated spontaneously breathing 2-4 year old child (23).

\section{ULTRASONIC NEBULIZERS}

Ultrasonic nebulizers incorporate a piezoelectric crystal vibrating at high frequencies (1-3 MHz) in order to produce aerosol. They are divided into two categories (1) large-volume ultrasonic nebulizers and (2) small-volume ultrasonic nebulizers. Whereas large-volume ultrasonic nebulizers are most commonly used to deliver hypertonic saline for sputum induction, small-volume ultrasonic nebulizers are used for delivery of inhaled medications. Ultrasonic nebulizers have many limitations compared to jet nebulizers. For instance, they have large residual volumes, an inability to aerosolize viscous solutions, and degradation of heat-sensitive materials. Therefore, they should not be used with suspensions and proteins $(10,11,24,25)$.

\section{MESH NEBULIZERS}

Recent improvements in nebulizer technologies have led to the development of mesh nebulizers using micropump technology for aerosol production. They force liquid medications through multiple apertures in a mesh or aperture plate in order to generate aerosol. As small and portable nebulizers that are powered by either battery or electricity, they have silent operation, short treatment times, increased output efficiency, and minimal residual volume $(9,12,26-28)$. Advantages of mesh nebulizers include consistent and improved aerosol generation efficiency, a predominantly fine-particle fraction reaching into the peripheral lung, low residual volume, and the ability to nebulize in low drug volumes. The size of the pore, the aerosol chamber, and the reservoir, as well as the output rate of mesh nebulizers, can be adjusted for different drugs in order to optimize aerosol drug delivery to patients (27). Comparisons of mesh and ultrasonic nebulizers demonstrated similar drug delivery in simulated ventilator-dependent patients $(29,30)$. Mesh nebulizers are more efficient than jet nebulizers and can provide higher drug doses to patients. Although human studies with mesh nebulizers are limited, in vitro studies demonstrated approximately 2-3 times higher lung deposition with mesh nebulizers when compared to jet nebulizers $(31,32)$. Due to the higher efficiency of mesh nebulizers, the dosages of drug formulations may need to be adjusted in order to prevent the development of adverse effects because of overdose. Therefore, patients should be monitored closely during treatment for clinical responses and side effects.

Despite many advantages of these nebulizers, there are challenges associated with mesh nebulizers. For instance, delivery of viscous 
drugs and suspensions can clog the pores, and it can be difficult to determine from the output of the device. Also, cleaning of mesh nebulizers can be difficult. These nebulizers are also more expensive than jet nebulizers.

Mesh nebulizers can be classified into two categories: (1) active mesh nebulizers and (2) passive mesh nebulizers. Active mesh nebulizers use a piezo element that contracts and expands on application of an electric current and vibrates a precisely drilled mesh in contact with the medication in order to generate aerosol. Passive mesh nebulizers use a transducer horn that induces passive vibrations in the perforated plate with 6000 tapered holes to produce aerosol. Examples of active mesh nebulizers include the Aeroneb ${ }^{\circledR}$ (Aerogen, Galway, Ireland) and the eFlow ${ }^{\circledR}$ (PARI, Starnberg, Germany), while the Microair NE-U22 ${ }^{\circledR}$ (Omron, Bannockburn, IL) is a passive mesh nebulizer. Each type of mesh nebulizer is explained in more detail below.

\section{Active Mesh Nebulizers}

Aeroneb (Aerogen, Galway, Ireland): Aeroneb nebulizers are used for both spontaneously breathing and ventilator-dependent patients. While the Aeroneb ${ }^{\circledR} \mathrm{Go}$ is a portable compact handheld nebulizer, the Aeroneb ${ }^{\oplus}$ Solo is used for aerosol delivery via invasive and noninvasive ventilation. The Aeroneb ${ }^{\circledR}$ NIVO is used for aerosol delivery during noninvasive ventilation. All of them are assembled easily, have silent operation and short treatment duration, and are easy to clean. These features make it a more desirable nebulizer for patients and caregivers than jet nebulizers. Although the Aeroneb is a very efficient nebulizer that can administer a variety of drug formulations, there are some limitations with their use. For instance, they are expensive nebulizers that have a finite operational life span due to their vibrating piezoelectric element. Precipitation and crystallization of drug particles can clog the apertures that lead to inefficiency in aerosol drug delivery to patients. Also, using detergents during cleaning can damage the nature of the nebulizer. While the Aeroneb Solo and NIVO provide an airtight seal in the ventilator circuit as an in-line device, their controller units limit their portability, unlike the Aeroneb Go.

eFlow ${ }^{\circledR}$ (PARI, Starnberg, Germany): The PARI eFlow is a battery-operated, compact, portable nebulizer using the ODEM TouchSpray atomizing head that consists of a membrane with 4,000 laser-drilled apertures surrounded by a piezoelectric actuator to generate aerosol. It is a highly efficient nebulizer that provides approximately $90 \%$ of the nominal dose in a short treatment duration. Recent studies showed that the eflow can improve patient compliance due to short nebulization time (33). Also, the eFlow has a range of optimal fill volumes up to $4 \mathrm{ml}$ and can be used with a variety of drug formulations, such as highly viscous fluids, proteins, peptides, suspensions, and surfactants. Nebulization with the eFlow is highly efficient at approximately $90 \%$ of the charge dose, with aerosol output at rates up to $1 \mathrm{ml} / \mathrm{min}$, which leads to a short treatment duration. Mesh nebulizers, such as the e-Flow, should be repeatedly washed and disinfected in order to prevent possible microbiological contamination with cystic fibrosis patients. Previous studies showed that the performance of jet nebulizers was influenced by washing and disinfecting (34-36). However, no significant performance change in the e-Flow was found (37).

\section{Passive Mesh Nebulizers}

Microair NE-U22 (Omron, Bannockburn, IL): The Microair is a passive mesh nebulizer that employs mesh technology in order to provide efficient aerosol drug delivery with a predominantly fine-particle fraction. Just like other mesh nebulizers, it does not cause the denaturation or inactivation typically associated with the shear forces or reservoir heat generated with jet or ultrasonic nebulizers (12). However, there are potential problems with the MicroAir. It is an expensive nebulizer and hard to clean, as it has to be disassembled and cleaned after each use in order to prevent clogging of the mesh apertures. The treatment time may be shortened if concentrated solutions are used for therapy. Position of the Omron mesh nebulizer influences treatment time and variability in particle distribution (38). Although drug delivery with the Omron was greater in the horizontal position than the tilted position, its aerosol deposition was similar to a jet nebulizer (38).

\section{Smart Nebulizers}

Smart nebulizers employ adaptive aerosol delivery (AAD $\left.{ }^{\circledR}\right)$ technology, which analyzes the patient's breathing pattern in order to determine the timing of aerosol drug delivery during inhalation. They analyze pressure changes of the airflow during the first 3 breaths to determine the correct starting point for drug delivery. Then, the device continues to monitor the preceding 3 breaths throughout the treatment and adapts to the patient's breathing pattern. This adaptation reduces not only losses of aerosol during expiration but also the variation in drug delivery during inhalation therapy while improving patient adherence to treatment (39-41). Smart nebulizers also provide the patient with feedback about their effectiveness in using the device during therapy. Once the preset dose has been delivered to the patient, the device turns off and a buzzer indicates completion of treatment. There are a variety of new formulations for pulmonary delivery available on the market, and the need for better control over delivered doses of expensive drugs becomes particularly important, because continuous jet nebulizers waste $60-70 \%$ of a dose during exhalation. Also, breathing patterns impact drug deposition in the lung. For instance, nebulization at the end of inspiration will most likely not reach the lung. Therefore, it is important to adapt aerosol drug delivery based on patients' breathing patterns using smart nebulizers, such as the I-neb (Philips Respironics, Newark, USA) and AKITA (Activaero, Gemunden/Wohra, Germany). Thus, more accurate and reproducible drug delivery to patients with pulmonary diseases may be achieved.

I-neb (Philips Respironics, Newark, USA): The I-neb adaptive aerosol delivery $\left(A A D^{\circledR}\right)$ nebulizer (Philips Respironics, Newark, USA) is a small, lightweight, battery-powered, and silent smart nebulizer that combines mesh technology with $\mathrm{AAD}^{\circledR}$ technology in order to deliver a precise, reproducible dose. The I-neb $A A D^{\circledR}$ uses multiple-breath technology that is programmed with the inhalation dose. Through AAD technology, the timing of aerosol delivery is determined based on the patient's breathing pattern in order to improve the precision and reproducibility of dosing. In other words, a computer that is used with these technologies learns how the patient is breathing and adapts to changes in this breathing pattern, averaged over a series of breaths. The I-neb monitors peak flow of a patient's first three inhalations in order to determine the duration of aerosol production needed to target the beginning of a breath. Since the nebulizer produces aerosols only during the first half of inspiration, aerosols navigate the bronchial tree and reach the deep lung. Patients using these nebulizers receive feedback when the dose is delivered. Also, the device creates a data logger that acts as an electronic diary to help clinicians assess patient adherence. The dose-metering chamber has a low 
Table 1. Advantages and disadvantages of different types of nebulizers

\begin{tabular}{|c|c|c|}
\hline Nebulizers & Advantages & Disadvantages \\
\hline $\begin{array}{l}\text { Breath-actuated \& Breath-enhanced } \\
\text { jet nebulizers }\end{array}$ & $\begin{array}{l}\text { - Drug delivery only during inhalation } \\
\text { - Easy to use } \\
\text { - Less medication wasted } \\
\text { - More efficient than JNs with tubing }\end{array}$ & $\begin{array}{l}\text { - Need sufficient flow to trigger drug delivery } \\
\text { - Takes longer to deliver drug } \\
\text { - Not ventilator-enabled } \\
\text { - More expensive }\end{array}$ \\
\hline Ultrasonic nebulizers & $\begin{array}{l}\text { - Easy to use } \\
\text { - More efficient than jet nebulizers }\end{array}$ & $\begin{array}{l}\text { - Large residual volume } \\
\text { - Inability to aerosolize viscous solutions } \\
\text { - Degradation of heat-sensitive materials }\end{array}$ \\
\hline Mesh nebulizers & $\begin{array}{l}\text { - Fast, quiet, portable } \\
\text { - Self-contained power source } \\
\text { - Optimize particle size for specific drugs } \\
\text { - More efficient than other nebulizers } \\
\text { - Easy to use }\end{array}$ & $\begin{array}{l}\text { - More expensive } \\
\text { - Cleaning can be difficult } \\
\text { - Medication dosage must be adjusted in } \\
\text { transition from JNs } \\
\text { - Not compatible with viscous liquids or } \\
\text { those that crystallize on drying }\end{array}$ \\
\hline
\end{tabular}

residual volume and comes in various sizes to accommodate the dose requirements of different drug formulations.

The I-neb has two different breathing patterns: (1) the tidal breathing mode (TBM) and (2) the target inhalation mode (TIM). In the TBM, the device continuously monitors the patient's breathing pattern and adapts any changes based on the average. Then, the device delivers aerosolized medication in the first $50 \%$ to $80 \%$ of inspiration in order to minimize the amount of drug wasted during exhalation. In the TBM mode, the device has no control over a patient's breathing pattern. The patient decides how fast or slow she/he is going to breathe. However, in the TIM, the device guides patients to take a slow and deep breath through a tactile stimulus, coaching them to inhale very slowly based on their capability (41).

The I-neb AAD system improves inhaled alpha1-antitrypsin delivery through inspiration-only aerosol delivery and low residual volume. Slow, deep, and controlled inspirations using the I-neb AAD system is an efficient method to deliver inhaled alpha1-antitrypsin for treatment of cystic fibrosis to protect the lungs from excessive free elastase (42). Previous research indicates increased ease of use and more satisfaction with the I-neb AAD system than with other nebulizers available on the market, and it was also shown that the I-neb AAD system significantly improves dyspnea and fatigue in patients with chronic obstructive pulmonary disease compared to other nebulizers (42). Aerosol deposition with slow and deep inhalation in the TIM was significantly superior to drug delivery achieved during tidal breathing in the TBM. However, the nebulization time in the TIM is shorter than in the TBM (43).

The AKITA (Activaero, Gemunden/Wohra, Germany): The AKITA is a breath-actuated nebulizer that has no aerosol production on exhalation. It can be combined with a standard jet or mesh nebulizer for pulmonary delivery. The AKITA nebulizer individualizes patient aerosol delivery using a computer algorithm and personal "Smart Cards" that calibrate the device and track patient adherence to therapy (44). Through controlled breathing, the AKITA provides appropriate dosing that results in high efficiency and low variability in aerosol drug delivery to patients with pulmonary diseases. Despite the advantages of the AKITA in aerosol drug delivery, it is important to note that the AKITA is a large, less portable nebulizer that has a long treatment time. Also, there is not enough evidence about its use in infants and children with pulmonary diseases.

\section{OPTIMUM USE OF NEBULIZERS IN CLINICAL PRACTICE}

There are many factors affecting aerosol drug delivery to patients with pulmonary delivery. Successful inhalation therapy is technique-dependent. Therefore, clinicians need to know the different types of nebulizers available for aerosol therapy, the optimum technique that needs to be used in clinical practice, and troubleshooting with each type of nebulizer. Table 1 explains the advantages and disadvantages of different types of nebulizers.

It must be noted that the gas flow and pressure used with jet nebulizers impact particle size and drug delivery. For instance, each jet nebulizer has a specific flow rate requirement, ranging from 2-10 L/ $\mathrm{min}$, that was determined by the manufacturer and listed on the device label. Failure to set the flow meter appropriately will produce large particles during aerosol therapy. Sometimes, clinicians prefer to use a compressor along with a jet nebulizer. However, it is important to know that jet nebulizers are designed to operate at 50 psi and that the use of a compressor producing 13 psi will increase particle size and decrease efficiency of the treatment. Therefore, jet nebulizers should either be used with compressors that match their intended designs or be operated with a flow rate that is recommended on the device label by the manufacturer.

While jet nebulizers are operated with either compressed air or oxygen, using a helium/oxygen mixture (heliox) with jet nebulizers has become popular in recent years, as delivering aerosol with heliox im- 
Table 2. Technique for jet, ultrasonic, and mesh nebulizers

\section{Optimum technique for jet nebulizers}

Correctly assemble the nebulizer.

Attach the appropriate interface (mouthpiece or mask) to the nebulizer.

Put medicine into the nebulizer cup. Do not exceed the volume recommended by the manufacturer.

Sit in an upright position.

Connect the nebulizer to a power source.

Breathe normally with occasional deep breaths until sputter occurs or until the end of nebulization.

Keep the nebulizer vertical during treatment.

If the treatment must be interrupted, turn off the flow meter to avoid waste.

Rinse the nebulizer with sterile or distilled water and allow to air dry.

\section{Optimum technique for ultrasonic, mesh, \& smart nebulizers}

Correctly assemble the nebulizer.

Attach the appropriate interface (mouthpiece or mask) to the nebulizer.

If applicable, follow manufacturer's instructions in performing a functionality test prior to the first use of a new nebulizer as well as after each disinfection to verify proper operation.

Put medicine into the nebulizer cup. Do not exceed the volume recommended by the manufacturer.

Sit in an upright position.

Turn on the power.

Follow the instructions for breathing technique that are recommended by the manufacturer.

If the treatment must be interrupted, turn off the unit to avoid waste.

At the completion of the treatment, disassemble and clean as recommended by the manufacturer. Do not touch the mesh during cleaning in order to prevent damage.

Table 3. Problems, causes, and solutions during aerosol drug delivery with jet, ultrasonic, and mesh nebulizers

\begin{tabular}{|c|c|c|}
\hline Problems & Causes & Solutions \\
\hline \multirow[t]{3}{*}{$\begin{array}{l}\text { Absent or low aerosol with jet } \\
\text { nebulizers }\end{array}$} & Loose or unattached connections. & $\begin{array}{l}\text { Check the connections and make sure that } \\
\text { they are properly attached. }\end{array}$ \\
\hline & Inappropriate flow meter setting. & $\begin{array}{l}\text { Check the flow meter setting and adjust the } \\
\text { flow accordingly. }\end{array}$ \\
\hline & $\begin{array}{l}\text { Obstruction in the orifice of the jet } \\
\text { nebulizer. }\end{array}$ & $\begin{array}{l}\text { Check the orifice of the jet nebulizer and } \\
\text { clear obstructions when needed. }\end{array}$ \\
\hline \multirow[t]{4}{*}{$\begin{array}{l}\text { The unit of mesh or ultrasonic } \\
\text { nebulizers does not operate }\end{array}$} & Incorrect battery installation & $\begin{array}{l}\text { Check the battery installation and reinstall, } \\
\text { if needed. }\end{array}$ \\
\hline & Disconnection in external power source. & $\begin{array}{l}\text { Check the connection with the AC adapter } \\
\text { and the electrical output. }\end{array}$ \\
\hline & Overheated unit. & $\begin{array}{l}\text { Turn off the unit, wait until it cools down and } \\
\text { restart the unit. }\end{array}$ \\
\hline & Malfunctioning electronics. & Replace the unit. \\
\hline
\end{tabular}

proves drug delivery up to $50 \%$ (45-48). Using the right flow rate with heliox-driven aerosol therapy is essential for optimum aerosol drug delivery. For instance, if heliox is used at the same flow rate as with air or oxygen, the particle size and aerosol output delivered by the jet nebulizer will be reduced due to the low density of heliox compared to air and oxygen. Therefore, the flow with heliox should be increased by 1.5-2 times to optimize aerosol drug delivery in patients with pulmonary diseases $(48,49)$.

Since jet nebulizers have large residual volumes of 0.5 to $2 \mathrm{~mL}$ and do not aerosolize below residual volume, they do not function well with small fill volumes, such as $2 \mathrm{~mL}$ or less. Therefore, clinicians should consider increasing the fill volume to improve the efficiency of jet nebulizers. Unless the nebulizer is specifically designed for a smaller fill volume, the use of a fill volume of 4-5 mL with jet nebulizers is recommended (6). Increasing the fill volume will dilute the medication and deliver a greater proportion of the dose. The only drawback of additional fill volume is the increase in treatment time with jet nebulizers.

Aerosolized drugs are administered using either a mouthpiece or a face mask. Although, the mouthpiece is the ideal interface to be used during aerosol therapy, it can not be used in infants, small children, and elderly who have cognitive problems. The face mask is the preferred interface in these cases, but use of a face mask increases the amount of aerosol deposited on the face, in the eyes, and into the nose. Also, it is important to achieve a good face mask seal for optimum drug delivery during aerosol therapy. Since optimum aerosol drug delivery is technique-dependent, it is important to instruct the patient to do tidal breathing through the mouth with periodic deep breaths during aerosol therapy. Table 2 describes the optimum techniques that should be used with jet, mesh, and ultrasonic nebulizers for aerosol drug delivery to patients with pulmonary diseases. Also, 
clinicians should be aware of potential problems that may occur with the use of each nebulizer during aerosol therapy. They should know what the underlying causes of each problem are and how to solve them. Table 3 explains the problems, causes, and solutions during aerosol drug delivery with jet, ultrasonic, and mesh nebulizers.

In conclusion, aerosol therapy via nebulizers is a well-established method for treatment of patients with pulmonary diseases. Recent advances in the development of nebulizers have made drug delivery more precise, less wasteful, and potentially much easier to use during inhalation therapy. Also, new types of nebulizers have yielded a number of improvements, such as compact design, portability, shorter treatment duration, and quiet operation, that are expected to improve patient adherence to therapy. However, despite developments in aerosol technologies, there is still a need to reduce the costs of these new nebulizers.

Peer-review: Internally peer-reviewed.

Acknowledgements: I would like to thank Dr. Benan Çağlayan, Dr. Gülderen Şahin and all members of the Inhalation Treatments Working Group for their support in writing this manuscript.

Conflict of Interest: No conflict of interest was declared by the authors.

Financial Disclosure: The author declared that this study has received no financial support.

\section{REFERENCES}

1. Yoshiyama $\mathrm{Y}$, Yazaki T, Arai M, Asai K, Kanke M. The nebulization of budesonide suspensions by a newly designed mesh nebulizer. Respiratory Drug Delivery 2002; VIII: 487-9.

2. Elhissi A, Karnam KK, Danesh-Azari MR, Gill HS, Taylor KM. Formulations generated from ethanol-based proliposomes for delivery via medical nebulizers. J Pharm Pharmacol 2006; 58: 887-94. [CrossRef]

3. Elhissi A, Taylor K. Delivery of liposomes generated from proliposomes using air-jet, ultrasonic and vibrating mesh nebulizers. J Drug Del Sci Tech 2005; 15: 261-5.

4. Wagner A, Vorauer-Uhl K, Katinger H. Nebulization of liposomal rh-Cu/ Zn-SOD with a novel vibrating membrane nebulizer. J Liposome Res 2006; 16: 113-25. [CrossRef]

5. LentzYK, Anchordoguy TJ, Lengsfeld CS. Rationale for the selection of an aerosol delivery system for gene delivery. J Aerosol Med 2006; 19: 372-84. [CrossRef]

6. Hess D, Fisher D, Williams P, Pooler S, Kacmarek RM. Medication nebulizer performance. Effects of diluent volume, nebulizer flow, and nebulizer brand. Chest 1996; 110: 498-505. [CrossRef]

7. Zainudin B, Biddiscombe M, Tolfree SE, Short M, Spiro SG. Comparison of bronchodilator responses and deposition patterns of salbutamol inhaled from a pressurised metered dose inhaler, as a dry powder, and as a nebulised solution. Thorax 1990; 45: 469. [CrossRef]

8. Smith EC, Denyer J, Kendrick AH. Comparison of twenty three nebulizer/compressor combinations for domiciliary use. Eur Repir J 1995; 8: 1214-21. [CrossRef]

9. Ari A, Hess D, Myers TR, Rau JL. A guide to aerosol delivery devices for respiratory therapists. 2nd ed. Dallas, Texas: American Association for Respiratory Care; 2009.

10. Ari A, Fink J Guidelines for aerosol devices in infants, children and adults: which to choose, why and how to achieve effective aerosol therapy? Expert Rev Respir Med 2011; 5: 561-72. [CrossRef]

11. Ari A, Restrepo RD, American Association for Respiratory Care. Aerosol delivery device selection for spontaneously breathing patients: 2012 . Respir Care 2012; 57: 613-26. [CrossRef]

12. Waldrep JC, Dhand R. Advanced nebulizer designs employing vibrating mesh/aperture plate technologies for aerosol generation. Curr Drug Deliv 2008; 5: 114-9. [CrossRef]
13. Hoffman L, Smithline H. Comparison of Circulaire to conventional small volume nebulizer for the treatment of bronchospasm in the emergency department. Respir Care 1997; 42: 1170-4.

14. Mason J, Miller W, Small S. Comparison of aerosol delivery via Circulaire system vs conventional small volume nebulizer. Respir Care 1994; 39: 1157-61.

15. Mason J, Miller W. Comparison of aerosol delivery via Circulaire nebulizer system versus a disposable nebulizer in COPD patients. Respir Care 1996; 41: 1006-8.

16. Piper SD. In vitro comparison of the circulaire and Aero Tee to a traditional nebulizer T-piece with corrugated tubing. Respir Care 2000; 45: 313-9.

17. Coates AL, MacNeish CF, Lands LC, Meisner D, Kelemen S, Vadas EB. A comparison of the availability of tobramycin for inhalation from vented vs unvented nebulizers. Chest 1998; 113: 951-6. [CrossRef]

18. Dennis J. Drug nebulizer design and performance: breath enhanced jet versus ultrasonic. J Aerosol Med 1995; 8: 277-80. [CrossRef]

19. Ho SL, Kwong WT, O'Drowsky L, Coates AL. Evaluation of four breath-enhanced nebulizers for home use. J Aerosol Med 2001; 14:467-75. [CrossRef]

20. Rau JL, Ari A, Restrepo RD. Performance comparison of nebulizer designs: constant-output, breath-enhanced, and dosimetric. Respiratory Care 2004; 49: 174-9.

21. Arunthari V, Bruinsma RS, Lee AS, Johnson MM. A prospective, comparative trial of standard and breath-actuated nebulizer: efficacy, safety, and satisfaction. Respir Care 2012; 57: 1242-7. [CrossRef]

22. Haynes J. Randomized controlled trial of a breath-activated nebulizer in patients with exacerbation of COPD. Respir Care 2012; 57: 1385-90. [CrossRef]

23. Lin HL, Wan GH, Chen YH, Fink JB, Liu WQ, Liu KY. Influence of nebulizer type with different pediatric aerosol masks on drug deposition in a model of a spontaneously breathing small child. Respir Care 2012; 57: 1894-900. [CrossRef]

24. Watts AB, McConville JT, Williams RO 3rd. Current therapies and technological advances in aqueous aerosol drug delivery. Drug Dev Ind Pharm 2008; 34: 913-22. [CrossRef]

25. Taylor K. Ultrasonic nebulizers for pulmonary drug delivery. Int $J$ Pharm1997; 153: 93-104. [CrossRef]

26. Rau JL. The inhalation of drugs: advantages and problems. Respir Care 2005; 50: 367-82.

27. Dhand R. Nebulizers that use a vibrating mesh or plate with multiple apertures to generate aerosol. Respir Care 2002; 47: 1406-16.

28. Dolovich MB, Dhand R. Aerosol drug delivery: developments in device design and clinical use. Lancet 2010; 377: 1032-45. [CrossRef]

29. Pedersen $\mathrm{K}$, Handlos V, Heslet L, Kristensen H. Factors influencing the in vitro deposition of tobramycin aerosol: a comparison of an ultrasonic nebulizer and a high-frequency vibrating mesh nebulizer. J Aerosol Med 2006; 19: 175-83. [CrossRef]

30. Ari A, Areabi H, Fink JB. Evaluation of aerosol generator devices at 3 locations in humidified and non-humidified circuits during adult mechanical ventilation. Respir Care 2010; 55: 837-44.

31. Ari A, Atalay OT, Harwood R, Sheard MM, Aljamhan EA, Fink JB. Influence of nebulizer type, position, and bias flow on aerosol drug delivery in simulated pediatric and adult lung models during mechanical ventilation. Respir Care 2010; 55: 845-51.

32. Vecellio L, De Gersem R, Le Guellec S, Reychler G, Pitance L, Le Pennec D, Diot $P$, Chantrel G, Bonfils $P$, Jamar F. Deposition of aerosols delivered by nasal route with jet and mesh nebulizers. Int J Pharm2011; 407: 87-94. [CrossRef]

33. Lenney W, Edenborough F, Kho P, Kovarik JM. Lung deposition of inhaled tobramycin with eFlow rapid/LC Plus jet nebuliser in healthy and cystic fibrosis subjects. J Cyst Fibros 2011; 10: 9-14. [CrossRef]

34. Standaert TA, Morlin GL, Williams-Warren J, Joy P, Pepe MS, Weber A, Ramsey BW. Effects of repetitive use and cleaning techniques of disposable jet nebulizers on aerosol generation. Chest 1998; 114: 577-86. [CrossRef] 
35. Rosenfeld M, Joy P, Nguyen C, Krzewinski J, Burns J. Cleaning home nebulizers used by patients with cystic fibrosis: is rinsing with tap water enough? J Hosp Infect 2001; 49: 229-30. [CrossRef]

36. Tay ET, Needleman JP, Avner JR. Nebulizer and spacer device maintenance in children with asthma. J Asthma 2009; 46: 153-5. [CrossRef]

37. Bakuridze L, Andrieu V, Dupont C, Dubus JC. Does repeated disinfection of the e-Flow rapid nebulizer affect in vitro performance? J Cyst Fibrosis 2007; 6: 309-10. [CrossRef]

38. Skaria S, Smaldone GC. Omron NE U22: Comparison between vibrating mesh and jet nebulizer. J Aerosol Med Pulm Drug Deliv 2010; 23: 173-80. [CrossRef]

39. Nikander K. Adaptive aerosol delivery: the principles. Eur Respir Rev 1997; 7: 385-7.

40. Denyer J. Adaptive aerosol delivery in practise. Eur Respir Rev 1997; 7: 388-9.

41. Denyer J, Nikander K, Smith NJ. Adaptive aerosol delivery (AAD) technology. Expert Opin Drug Deliv 2004; 1: 165. [CrossRef]

42. Geller DE, Kesser KC. The I-neb adaptive aerosol delivery system enhances delivery of alpha1-antitrypsin with controlled inhalation. J Aerosol Med Pulm Drug Deliv 2010; 1: 55-9.
43. Nikander K, Prince I, Coughlin S, Warren S, Taylor G. Mode of breathing-tidal or slow and deep-through the I-neb Adaptive Aerosol Delivery (AAD) system affects lung deposition of (99m)Tc-DTPA. J Aerosol Med Pulm Drug Deliv 2010; 1: 37-43.

44. Rubin BK. Pediatric aerosol therapy: new devices and new drugs. Respir Care 2011; 56: 1411-21. [CrossRef]

45. Ari A, Harwood R, Sheard M, Dailey P, Fink JB. In vitro comparison of heliox and oxygen in aerosol delivery using pediatric high flow nasal cannula. Pediatr Pulmonol 2011; 46: 795-801. [CrossRef]

46. Ari A, Fink J. Aerosol drug delivery administration with helium-oxygen (heliox) mixtures: an overview. Current Respiratory Medicine Reviews 2010; 6: 80-5. [CrossRef]

47. Corcoran TE, Gamard S. Development of aerosol drug delivery with helium oxygen gas mixtures. J Aerosol Med 2004; 17: 299-309. [CrossRef]

48. Fink JB. Opportunities and risks of using heliox in your clinical practice. Respir Care 2006; 51: 651-60.

49. Hess DR, Acosta FL, Ritz RH, Kacmarek RM, Camargo CA Jr. The effect of heliox on nebulizer function using a beta-agonist bronchodilator. Chest 1999; 115: 184-9. [CrossRef] 